\title{
Rehabilitation Effects of Acupuncture on the Diaphragm Dysfunction in Chronic Obstructive Pulmonary Disease: A Systematic Review
}

\author{
Qinxin Liu' \\ Hongxia Duan (D) \\ Anbei Lian' \\ Min Zhuang ${ }^{1,2}$ \\ Xianli Zhao \\ Xiaodan Liu ${ }^{1,3}$ \\ 'School of Rehabilitation Science, \\ Shanghai University of Traditional \\ Chinese Medicine, Shanghai, People's \\ Republic of China; ${ }^{2}$ Department of \\ Rehabilitation, Huashan Hospital, Fudan \\ University, Shanghai, People's Republic of \\ China; ${ }^{3}$ Engineering Research Center of \\ Intelligent Rehabilitation of Traditional \\ Chinese Medicine, Ministry of Education, \\ Shanghai University of Traditional \\ Chinese Medicine, Shanghai, People's \\ Republic of China
}

Introduction: Diaphragm dysfunction is a significant extrapulmonary effect in chronic obstructive pulmonary disease (COPD), which is manifested by changes in diaphragm structure and reduced diaphragm strength. Acupuncture is a traditional rehabilitation technique in China, which has been used in rehabilitation for COPD. But whether acupuncture can improve the diaphragm function of COPD patients remains to be verified.

Objective: The objective of this study was to evaluate the rehabilitation effects of acupuncture on diaphragm dysfunction in patients with COPD.

Methods: The authors retrieved in CNKI, VIP, SinoMed, PubMed, Ebsco, Web of Science, from inception to November 2020, for relevant randomized control trials. Two researchers independently screened the articles and extracted the data. The quality of the included studies was evaluated by Physiotherapy Evidence Database scale. The primary outcome measures were maximal inspiratory pressure and the scale for accessory respiratory muscle mobilization, the secondary outcome measures were pulmonary function-related indicators and arterial blood gas indicators.

Results: Nine articles were finally obtained. Seven studies added acupuncture to standard treatment for patients with diaphragm dysfunction in COPD and found statistically significant changes in the maximum inspiratory pressure and the scale for accessory respiratory muscle mobilization. Two studies have proved that use acupuncture combined with other Traditional Chinese Medicine methods in the rehabilitation for COPD can effectively improve the diaphragm strength and diaphragmatic motor performance. Seven studies showed that acupuncture has obvious improvement in pulmonary ventilation function. Seven studies reported significant differences in arterial blood gas pre- to post-intervention. Conclusion: This systematic review found that acupuncture can effectively enhance the diaphragm strength, relieve respiratory muscle fatigue, it can also play a promoting role in improving lung function, hypoxia, and carbon dioxide retention, as well as preventing and alleviating respiratory failure. The generalizability of these results is limited by the design of the included studies.

Keywords: chronic obstructive pulmonary disease, diaphragm, dysfunction, acupuncture, rehabilitation effect

\section{Introduction}

Chronic obstructive pulmonary disease (COPD) is a leading cause of chronic morbidity and mortality worldwide and one of the top three causes of death throughout the world, representing an important public health challenge. ${ }^{1,2}$ In 2018, The Lancet reported that the total number of patients with COPD in China 
was about 100 million, and the prevalence among people over 40 years old reached $13.7 \%{ }^{3}$ As a chronic respiratory disease, COPD not only induces airway and lung injury but also has significant extrapulmonary effects, including diaphragm dysfunction, which is mainly characterized by changes in diaphragm structure, diaphragm atrophy, and decline of diaphragm muscle tone and endurance. ${ }^{4-7}$ The diaphragm is an essential skeletal muscle of the human body and plays an important role in many aspects of vital activities, especially in respiratory movement. The diaphragm participates in about $80 \%$ of the breathing process and is the main power source of respiratory movement. ${ }^{8}$ Therefore, when patients with COPD have diaphragm dysfunction, it will probably trigger other complications, such as dyspnea, restricted exercise capacity, and reduced quality of life, and may eventually cause respiratory failure or even death. ${ }^{9}$ Consequently, the rehabilitation for diaphragm dysfunction in COPD should be the focus in preventing and treating COPD. Pulmonary rehabilitation can effectively improve the diaphragm function in COPD; some routine pulmonary rehabilitation methods, such as exercise training and respiratory muscle training, have remarkable effects on enhancing diaphragm muscle strength, increasing exercise capacity, and relieving dyspnea. ${ }^{10,11}$ The emergence and development of diaphragm dysfunction in COPD is a complex process affected by various factors; as such, no explicit rehabilitation intervention program has been established. We need to explore more effective rehabilitation methods in addition to routine lung rehabilitation items.

The Global Initiative for Chronic Obstructive Lung Disease (GOLD) pointed out in the 2020 report on the Global Strategy for COPD diagnosis, treatment and prevention that different countries should develop distinctive pulmonary rehabilitation programs according to their cultural background. ${ }^{1}$ Acupuncture is a characteristic rehabilitation method guided by the theory of Traditional Chinese Medicine under the background of Chinese traditional culture; in this process, needles are stuck into the skin and underlying tissues to stimulate certain acupoints and achieve the purpose of preventing and treating diseases. Acupuncture has been widely used in pulmonary rehabilitation for many respiratory diseases, including COPD. ${ }^{12}$ Acupuncture can effectively regulate lung ventilation and improve peripheral skeletal muscle dysfunction in patients with COPD. ${ }^{13}$ In the rehabilitation for COPD, acupuncture shows advantages in improving the therapeutic efficacy and safety. Juan et $\mathrm{al}^{14}$ reported that acupuncture combined with exercise therapy can reduce exercise-induced fatigue, which is a side effect of exercise, and improve the effect of pulmonary rehabilitation in patients with stable COPD. In recent years, some clinical trials and basic studies in China have begun to be concerned with the effect of acupuncture on diaphragm function in COPD. Acupuncture can achieve a similar effect in relieving diaphragm atrophy and diaphragm fatigue as other pulmonary rehabilitation methods ${ }^{15-17}$ hence, acupuncture has potential in rehabilitation for diaphragm dysfunction in COPD.

After reviewing relevant studies, some investigators observed that acupuncture has positive effects on the exercise capacity and quality of life in COPD. ${ }^{18-20}$ However, these reviews do not compare the diaphragm function before and after intervention, and they have a broad definition of acupuncture. The following methods are included in the scope of acupuncture treatment: moxibustion, acupoint pressing, point application, and cupping. Hence, the rehabilitation effect of acupuncture on diaphragm dysfunction in COPD is not clear and needs to be explored. Our study summarizes and analyzes the application and effects of acupuncture, an invasive technique, on diaphragm dysfunction in COPD to provide support for follow-up research and clinical practice.

\section{Methods}

The design and execution of this study was referred to Preferred Reporting Items for Systematic Reviews and Meta-Analysis (PRISMA) guidelines and PRISMA for acupuncture (PRISMA-A).

\section{Inclusion and Exclusion Criteria Inclusion Criteria}

1) Type of studies: randomized controlled trials (RCTs); 2) Participants: males and females with stable COPD or acute exacerbation of COPD (AECOPD); 3) Interventions: the control group received either standard treatments or standard treatments plus sham acupuncture, in which standard treatment included but was not limited to health education, medication (anti-inflammatory, dilated bronchi, etc), or mechanical ventilation, etc; the observation group should be combined with acupuncture treatment on the basis of the control group (acupuncture combined with other Traditional Chinese Medicine treatments were also included), the type of acupuncture must be the invasive treatment with needles, such as filiform needle acupuncture, warming acupuncture, abdominal acupuncture, electric acupuncture, etc; 4) Primary 
outcomes: A. Diaphragm function: maximal inspiratory pressure (MIP), the scale for accessory respiratory muscle mobilization (ARMM), diaphragmatic excursion (DE), diaphragm thickening fraction (DTF), DE/time to peak inspiratory amplitude of the diaphragm (DE/TPIA $\left.\mathrm{dia}_{\mathrm{a}}\right)$, diaphragmaticrapid shallow breathing index (D-RSBI); 5) Secondary outcomes: A. Lung function: forced vital capacity (FVC), forced expiratory volume in one second (FEV1), the percentage of predicted values of FEV1 (FEV1\%pred), FEV1/FVC ratio (FEV1/FVC\%), maximal voluntary ventilation (MVV), vital capacity (VC); B. Arterial blood gases: arterial partial pressure of oxygen $\left(\mathrm{PaO}_{2}\right)$, arterial partial pressure of carbon dioxide $\left(\mathrm{PaCO}_{2}\right)$.

\section{Exclusion Criteria}

1) duplicated data; 2) not RCT; 3) inconsistent with our intervention measures, such as moxibustion, acupoint application or acupoint pressing; 4) outcomes outside the specified range.

\section{Data Collection}

Six databases (CNKI, VIP, SinoMed, PubMed, Ebsco, and Web of Science) were used as data resources to retrieve randomized controlled trials from inception to November 2020. We used the following search language in PubMed: ("Pulmonary Disease, Chronic Obstructive" [Mesh]) AND ("Acupuncture" [Mesh] OR "Acupuncture Therapy" [Mesh]) AND (respiratory muscle [All Fields] OR diaphragm [All Fields]). We used the following search language in Ebsco: (MM "Pulmonary Disease, Chronic Obstructive+") AND (MM "Acupuncture" OR MM "Acupuncture Therapy+") AND (TX respiratory muscle OR TX diaphragm). In the four other databases, the search was conducted with keywords in China or English, including chronic obstructive pulmonary disease (COPD OR COAD OR chronic obstructive lung disease OR chronic obstructive airway disease OR chronic airflow obstruction) and acupuncture (acupuncture therapy OR electroacupuncture OR warm acupuncture OR abdominal acupuncture) and diaphragm (respiratory muscle).

\section{Study Selection}

Based on the inclusion and exclusion criteria, two reviewers independently screened studies. They used the literature manager, EndNote, to found and removed the duplicate studies. Then, the title and abstract were browsed to exclude a part of irrelevant studies. Finally, the reviewers conducted the screening again by reading the full text of the remaining studies, excluded the studies that did not meet the criteria. In case of discordance between two reviewers, third parties intervened, discussed and reached consensus.

\section{Data Extraction and Analysis}

Two reviewers independently extracted data from the selected studies. The following information was extracted from each included study: first author, the year of publication, disease severity level, sample size, intervention measures, acupuncture scheme (acupoints, type of acupuncture, stimulation time, acupuncture frequency, and treatment duration), and outcomes. All the information was summed up in two data extraction tables. The high-frequency selected acupoints (selected times $\geq 4$ ) counted in included studies were accepted site association analysis, special acupoint association analysis, and meridian association analysis.

\section{Study Quality Assessment}

Two reviewers independently assessed the methodological features of each identified study using the Physiotherapy Evidence Database (PEDro) scale, which is a useful instrument for assessing the methodological quality of rehabilitation trials. ${ }^{21}$ The scale measures the 11 factors: eligibility criteria; random allocation; concealed allocation; baseline similarity; blinding of subjects, therapists, and assessors; measures of key outcomes for $>85 \%$ of the subjects; intention-to-treat analysis; between-group statistical comparisons; and point measures. Each fact corresponds to a yes-or-no question. The second to tenth questions are worth 1 point each (yes scores 1 point, no scores 0 ). The full score is 10 , the higher the score, the higher the quality of the study (see Table 1 for the details of the scale, more information about the scale can be obtained at https:// pedro.org.au/english/resources/pedro-scale/).

\section{Results}

\section{Studies Retrieved}

The initial search identified 186 records from electronic databases, and 1 additional record was identified by manual searching from reference checking. After screening for duplicate records, we included 152 articles and excluded 34 articles. Subsequent to title and abstract screening, 99 articles were excluded. We searched for the full text of the reserved 53 articles, then 44 studies were excluded (duplicate publications $=$ 5; not match with our intervention measures $=10$; not 
Table I The Physiotherapy Evidence Database Scale

\begin{tabular}{|c|c|c|}
\hline I. Eligibility criteria were specified & No & Yes \\
\hline $\begin{array}{l}\text { 2. Subjects were randomly allocated to groups (in } \\
\text { a crossover study, subjects were randomly allocated an } \\
\text { order in which treatments were received) }\end{array}$ & No & Yes \\
\hline 3. Allocation was concealed & No & Yes \\
\hline $\begin{array}{l}\text { 4. The groups were similar at baseline regarding the } \\
\text { most important prognostic indicators }\end{array}$ & No & Yes \\
\hline 5. There was blinding of all subjects & No & Yes \\
\hline $\begin{array}{l}\text { 6. There was blinding of all therapists who administered } \\
\text { the therapy }\end{array}$ & No & Yes \\
\hline $\begin{array}{l}\text { 7. There was blinding of all assessors who measured at } \\
\text { least one key outcome }\end{array}$ & No & Yes \\
\hline $\begin{array}{l}\text { 8. Measures of at least one key outcome were obtained } \\
\text { from more than } 85 \% \text { of the subjects initially allocated to } \\
\text { groups }\end{array}$ & No & Yes \\
\hline $\begin{array}{l}\text { 9. All subjects for whom outcome measures were } \\
\text { available received the treatment or control condition as } \\
\text { allocated or, where this was not the case, data for at } \\
\text { least one key outcome was analysed by "intention to } \\
\text { treat" }\end{array}$ & No & Yes \\
\hline $\begin{array}{l}\text { 10. The results of between-group statistical comparisons } \\
\text { are reported for at least one key outcome }\end{array}$ & No & Yes \\
\hline $\begin{array}{l}\text { II. The study provides both point measures and } \\
\text { measures of variability for at least one key outcome }\end{array}$ & No & Yes \\
\hline
\end{tabular}

$\mathrm{RCT}=2$; none of interest outcomes $=27$ ). Ultimately, nine articles were included (eight in Chinese and one in English). Figure 1 shows the detailed search flow. The characteristics of the 9 included studies are shown in Table 2. Considering the limitations may cause by the small number of included studies, the heterogeneity of acupuncture scheme design and the large difference in evaluation indicators, we chose vote counting based on direction of effect as the result synthesis method.

\section{Quality Assessment}

The quality and domain scores for each study are presented individually in Table 3, with a mean value of 6 . Seven studies scored 6 points, ${ }^{17,22,24-28}$ one scored 7 points, ${ }^{16}$ one scored 8 points. ${ }^{23}$ All studies reported eligibility criteria, random allocation, baseline similarity, measures of key outcomes for $>85 \%$ of the subjects, intention-to-treat analysis, group comparison, and point measures. One study reported concealed allocation. $^{23}$ One study implemented blinding of subjects. $^{23}$ One study reported the blinding of assessor (assess the lung function). ${ }^{16}$ None of the studies implemented blinding of therapists, due to the difficulty in administering blindness when acupuncture.

\section{Intervention Measure: Acupuncture}

The acupuncture schemes used for patients with diaphragm dysfunction in COPD are not consistent in the included studies. The diversity is reflected in five aspects: type of acupuncture, acupoints, stimulation time, acupuncture frequency, and treatment duration. Table 4 lists the details of acupuncture scheme in each study.

\section{Type of Acupuncture}

Four types of acupuncture were used in the included studies: filiform needle acupuncture (three studies selected), ${ }^{17,23,26}$ warming acupuncture (two studies selected), ${ }^{22,25}$ abdominal acupuncture (three studies selected), ${ }^{16,27,28}$ and big-needle acupuncture (one study selected). ${ }^{24}$ Warming acupuncture means that after filiform needle acupuncture, moxa wool is wrapped in the tail of the needle and lit to warm up. Abdominal acupuncture is a type of acupuncture for treating diseases through filiform needle acupuncture at abdominal acupoints. Big-needle acupuncture refers to acupuncture by a special needle with $0.45-1 \mathrm{~mm}$ in diameter and 4-7 inches in length, which is longer and thicker than ordinary filiform needle, and its retention time is also longer than filiform needle acupuncture.

\section{Acupoints}

Although the included studies varied in acupoint selection, but we counted the top 7 acupoints that were selected more frequently: ST36, ${ }^{17,22,23,25,36}$ CV12, ${ }^{16,17,23,27,28}$ CV4, ${ }^{16,17,23,27,28} \quad$ CV6, ${ }^{16,17,25,28} \quad$ SP15, ${ }^{16,17,27,28}$ BL13, ${ }^{22,23,25,26}$ and BL23. ${ }^{22,23,25,26}$ We carried out site association analysis, special acupoint association analysis, and meridian association analysis on high-frequency selected acupoints. Except ST36, the six other acupoints were located in abdomen or back. Considering that abdominal acupuncture has the characteristic of selecting acupoints in the abdomen, which will affect the results of acupoint-site association analysis, we excluded three studies in which abdominal acupuncture was selected, then re-counted the other six studies. ${ }^{17,22-26}$ It is found that four (BL13, BL23, BL20, EX-B1) of the top six acupoints with high utilization rate in the six studies are located in the back. All highfrequency selected acupoints are specific acupoints, of which ST36 is both five-shu point and lower-he-sea point; CV12, CV4, and SP15 are crossing points; BL13 and BL23 are back-shu points; and CV6 is yuan-primary point. Seven acupoints are distributed on Yangming Stomach Meridian of Foot, Ren Meridian, Taiyin Spleen Meridian of Foot or Taiyang Bladder Meridian of Foot. In terms of the number 


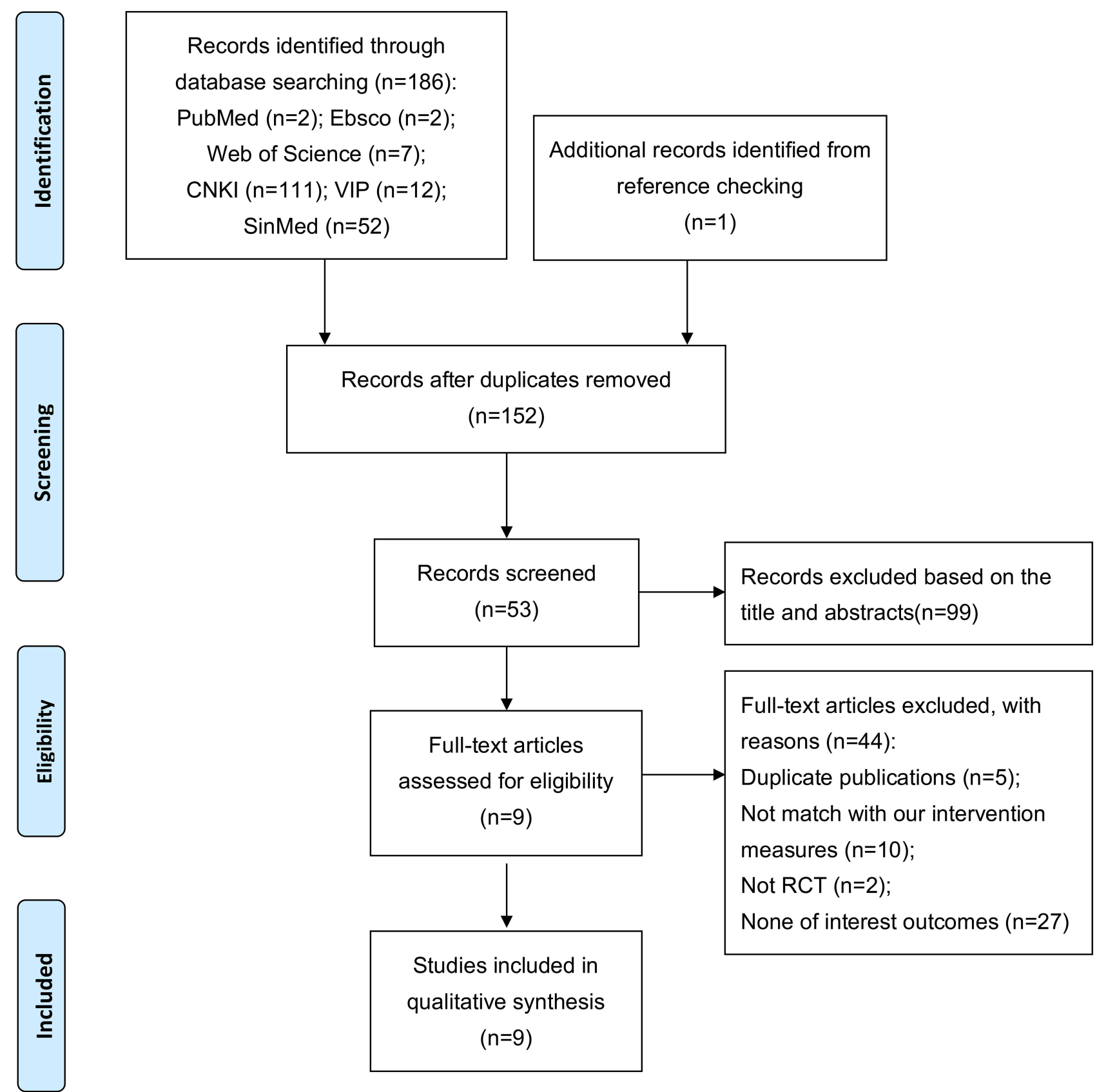

Figure I Systematic search flowchart.

of acupoints selected, most studies selected 6-12 acupoints, and only one study selected one acupoint. ${ }^{24}$

\section{Stimulation Time}

The stimulation time of acupuncture refers to the time that the needle retains on the acupoint for sustained stimulation after it pierces into the skin, which is affected by different type of acupuncture, ranged from 18 minutes to 4 hours in each study. Filiform needle acupuncture and abdominal acupuncture mostly retain the needle for 30 minutes; the stimulation time of warm acupuncture is calculated by the number of burning moxa sticks and expressed in Zhuang units, ranging from 3 to 5 Zhuang. The stimulation time of big-needle acupuncture is the longest, up to 4 hours.

\section{Acupuncture Frequency and Treatment Duration} Obvious differences were found in acupuncture frequency and treatment duration, and the information is incomplete. 
Table 2 Characteristics of Studies Included in This Review

\begin{tabular}{|c|c|c|c|c|c|c|}
\hline \multirow{2}{*}{$\begin{array}{l}\text { First } \\
\text { Author(Year) }\end{array}$} & \multirow[t]{2}{*}{ Patients } & \multicolumn{2}{|c|}{ Intervention } & \multicolumn{3}{|c|}{ Outcome } \\
\hline & & Observation Group & Control Group & $\begin{array}{l}\text { Diaphragm } \\
\text { Function }\end{array}$ & $\begin{array}{l}\text { Pulmonary } \\
\text { Function }\end{array}$ & $\begin{array}{c}\text { Arterial } \\
\text { Blood } \\
\text { Gases }\end{array}$ \\
\hline $\begin{array}{l}\text { Deng YQ } \\
(2019)^{22}\end{array}$ & $\begin{array}{l}\text { GOLD II- } \\
\text { III, stable } \\
\text { COPD }\end{array}$ & $\begin{array}{c}\text { Warming acupuncture+ } \\
\text { Standard therapy+ Rehabilitation } \\
\text { training }(n=45)\end{array}$ & $\begin{array}{l}\text { Standard therapy+ } \\
\text { Rehabilitation training }(n=45)\end{array}$ & MIP & $\mathrm{FVC}^{\#}$ & $\begin{array}{c}\mathrm{PaO}_{2}^{\#} \\
\mathrm{PaCO}_{2}^{\#}\end{array}$ \\
\hline $\begin{array}{l}\text { Suzuki } \\
M(20 I 2)^{23}\end{array}$ & $\begin{array}{l}\text { GOLD II- } \\
\text { IV, stable } \\
\text { COPD }\end{array}$ & $\begin{array}{l}\text { Filiform needle acupuncture }+ \\
\text { Standard therapy }(n=34)\end{array}$ & $\begin{array}{c}\text { Sham acupuncture }+ \text { Standard } \\
\text { therapy }(n=34)\end{array}$ & MIP & $\begin{array}{c}\text { FVC }^{\#} \\
\text { FEVI\%pred }^{\#}\end{array}$ & $\mathrm{PaO}_{2}^{\dagger}$ \\
\hline \multirow[t]{2}{*}{$\begin{array}{l}X u Y G \\
(2008)^{24}\end{array}$} & \multirow[t]{2}{*}{$\begin{array}{l}\text { GOLD III, } \\
\text { stable } \\
\text { COPD }\end{array}$} & \multirow[t]{2}{*}{$\begin{array}{l}\text { Big-needle acupuncture }+ \\
\text { Standard therapy }(n=20)\end{array}$} & $\begin{array}{l}\text { Filiform needle group: Filiform } \\
\text { needle acupuncture+ Standard } \\
\text { therapy }(n=20)\end{array}$ & MIP*\# & I & l \\
\hline & & & $\begin{array}{l}\text { Blank group: Standard therapy } \\
\qquad(n=20)\end{array}$ & & & \\
\hline $\operatorname{Lin}$ LJ $(2015)^{25}$ & $\begin{array}{l}\text { Stable } \\
\text { COPD }\end{array}$ & $\begin{array}{c}\text { Warming acupuncture }+ \text { Chinese } \\
\text { materia medica }+ \text { Standard } \\
\text { therapy }(n=40)\end{array}$ & Standard therapy $(n=40)$ & MIP*\# & $\begin{array}{c}\text { FEVI*\# } \\
\text { FVC\%*\# } \\
\text { FEVI/FVC*\# }\end{array}$ & 1 \\
\hline $\begin{array}{l}\text { Wu LL } \\
(2019)^{26}\end{array}$ & $\begin{array}{l}\text { GOLD II- } \\
\text { IV }\end{array}$ & $\begin{array}{c}\text { Filiform needle acupuncture }+ \\
\text { Shenmai injection }+ \text { Standard } \\
\text { therapy }(n=46)\end{array}$ & Standard therapy $(n=45)$ & $\begin{array}{c}\text { DE*\# } \\
\text { D-RSBI*\# } \\
\text { DTF*\# }^{* \#} \\
\text { DE/TPIA }{ }_{d i a}^{* \#}\end{array}$ & l & $\begin{array}{c}\mathrm{PaO}_{2}{ }^{* \#} \\
\mathrm{PaCO}_{2}{ }^{* \#}\end{array}$ \\
\hline $\begin{array}{l}\text { Guan } \\
W(2016)^{16}\end{array}$ & AECOPD & $\begin{array}{l}\text { Abdominal acupuncture+ } \\
\text { Standard therapy }(n=33)\end{array}$ & Standard therapy $(n=34)$ & ARMM & $\begin{array}{c}\text { FEVI/ } \\
\text { FVC**\#\# } \\
\text { FEVI\% } \\
\text { pred**\#\# } \\
\text { MVV\%**\#\# }\end{array}$ & $\begin{array}{l}\mathrm{PaO}_{2} * * \# \\
\mathrm{PaCO}_{2} * *\end{array}$ \\
\hline $\begin{array}{l}\text { Wang } \\
\text { Y }(2020)^{27}\end{array}$ & AECOPD & $\begin{array}{l}\text { Abdominal acupuncture+ } \\
\text { Standard therapy }(n=50)\end{array}$ & Standard therapy $(n=50)$ & ARMM*\# & $\begin{array}{l}\mathrm{FEVI} / \mathrm{FVC} * * \\
\text { MVV\%** }\end{array}$ & $\begin{array}{l}\mathrm{PaO}_{2} * * \# \\
\mathrm{PaCO}_{2} *\end{array}$ \\
\hline $\begin{array}{l}\text { Wang JY } \\
(2015)^{17}\end{array}$ & AECOPD & $\begin{array}{c}\text { Filiform needle acupuncture }+ \\
\text { Standard therapy }(n=32)\end{array}$ & Standard therapy $(n=31)$ & MIP**\#\# & $\begin{array}{l}\mathrm{FVC}^{\# \#} \\
\mathrm{FEVI/FVC} \\
\mathrm{MVV}^{* *}\end{array}$ & $\begin{array}{l}\mathrm{PaO}_{2} * * \# \\
\mathrm{PaCO}_{2} *\end{array}$ \\
\hline $\begin{array}{l}\text { Cheng YY } \\
(2017)^{28}\end{array}$ & AECOPD & $\begin{array}{l}\text { Abdominal acupuncture+ } \\
\text { Standard therapy }(n=34)\end{array}$ & Standard therapy $(n=34)$ & ARMM*\# & $\begin{array}{c}\text { VC\%* } \\
\text { FEVI/FVC*\# } \\
\text { FEVI\%pred*\# } \\
\text { MVV\%* }\end{array}$ & $\begin{array}{c}\mathrm{PaO}_{2} * \\
\mathrm{PaCO}_{2}^{*}\end{array}$ \\
\hline
\end{tabular}

Notes: /, not reported; *Compare the data between post-intervention and pre-intervention in the observation group, $P$ value $<0.05$; ${ }^{\#}$ Compare the post-intervention data between observation group and control group, $P$ value $<0.05$; **Compare the data between post-intervention and pre-intervention in the observation group, $P$ value $<0.0 \mathrm{I}$; ${ }^{\#}$ Compare the post-intervention data between observation group and control group, $P$ value $<0.01$; ${ }^{\dagger}$ Compare the changes from baseline to post-intervention data between the observation group and the control group, $P$ value $<0.05$.

Abbreviations: ARMM, the scale for accessory respiratory muscle mobilization; DE, diaphragmatic excursion; DTF, diaphragm thickening fraction; DE/TPIA dia, diaphragm contraction speed; FVC, forced vital capacity; FEVI, forced expiratory volume in one second; FEVI\%pred, forced expiratory volume in one second/prediction; FEVI/FVC\%, FEVI/FVC ratio; MIP, maximal inspiratory pressure; MVV, maximal voluntary ventilation; $\mathrm{PaO}_{2}$, arterial partial pressure of oxygen; $\mathrm{PaCO}$, arterial partial pressure of carbon dioxide; D-RSBI, diaphragmatic-rapid shallow breathing index; VC, vital capacity.

\section{Outcomes}

\section{Diaphragm Function}

All studies reported the indicators related to diaphragm function, and the changes in them during the treatment.
One study used ultrasound technology to record DE, DTF, DE/TPIA ${ }_{\text {dia }}$, D-RSBI of patient in COPD ${ }^{26}$ five studies chose measure MIP to monitor participants' diaphragm strength; ${ }^{17,22-25}$ three studies used AMRR to assess the 


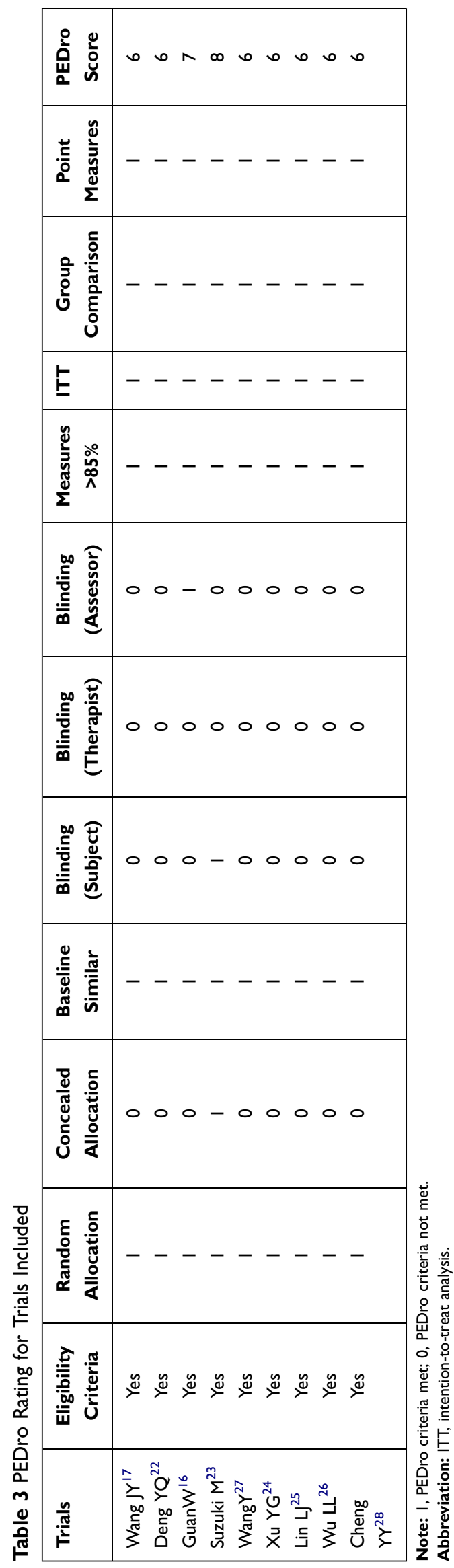

functional performance of main respiratory muscle, which include diaphragm. ${ }^{16,27,28}$

In a 12-week single-blind randomized controlled trial, Suzuki et $\mathrm{al}^{23}$ treated patients with stable COPD by using acupuncture for 50 minutes each time (11 acupoints were selected); they found that the MIP in the acupuncture group increased by 13.8 [13.0] $\left(\mathrm{H}_{2} \mathrm{Ocm}\right)$ compared with that before intervention, while the MIP in the sham acupuncture group decreased by 1.0 [11.9] $\left(\mathrm{H}_{2} \mathrm{O} \mathrm{cm}\right)$. Some Chinese scholars also interested in the changes in diaphragm function of patients with COPD after acupuncture was involved in rehabilitation. Deng et $\mathrm{al}^{22}$ added warming acupuncture five times a week to patients with stable COPD in the treatment group on the basis of the same intervention measures as the control group. The diaphragm muscle strength of patients in this group was more significantly improved compared with that in the control group that only received standard therapy and rehabilitation training. Wang et $\mathrm{al}^{17}$ treated patients with AECOPD by using filiform needle acupuncture and standard therapy. The results showed that the MIP of the treatment group was $3.82 \pm 1.37(\mathrm{kPa})$ after 40 days, which significantly differed from the MIP in parallel control group, which only received standard therapy $(P$ value $<0.01)$. A threearm RCT conducted by $\mathrm{Xu}$ et $\mathrm{al}^{24}$ showed that the MIP $\left(\mathrm{cmH}_{2} \mathrm{O}\right)$ in the big-needle acupuncture group after 4 weeks intervention was superior to that in the filiform needle acupuncture group ( $\mathrm{MD}=5.00$; $\mathrm{CI}$ : 1.80,8.20; $P$ value $=0.002)$ and in control group $(\mathrm{MD}=1.12$; $\mathrm{CI}$ : $0.45,1.80 ; P$ value $=0.001)$, MIP in the filiform needle acupuncture group after intervention was also significantly higher than that before intervention, but the results that compared with the control group were not clear. Another three studies used similar acupuncture schemes to perform abdominal acupuncture on patients with AECOPD in the observation group, on the basis of the same conventional treatment as the control group; they found that the ARMM was significantly reduced after the treatment, and the reduction was more obvious than that in the control group. $^{16,27,28}$

Two studies added acupuncture combined with Chinese herbal medicine to intervene in the observation group, based on the treatment methods in the control group. One study showed that the improvement of MIP $(\mathrm{kPa})$ in the observation group, which used warm acupuncture combined with Chinese herbal prescription, was more significant than that in the control group $(P$ value $<0.05){ }^{25}$ $\mathrm{Wu}$ et $\mathrm{al}^{26}$ used Shenmai injection combined with 
Table 4 Characteristics of Acupuncture Schemes of Included Study for Diaphragm Dysfunction in COPD

\begin{tabular}{|c|c|c|c|c|c|}
\hline $\begin{array}{l}\text { First } \\
\text { Author(Year) }\end{array}$ & Acupoints & $\begin{array}{c}\text { Type of } \\
\text { Acupuncture }\end{array}$ & $\begin{array}{l}\text { Stimulation } \\
\text { Time }\end{array}$ & Acupuncture Frequency & $\begin{array}{l}\text { Treatment } \\
\text { Duration }\end{array}$ \\
\hline $\begin{array}{l}\text { Deng YQ } \\
(2019)^{22}\end{array}$ & $\begin{array}{c}\text { BLI3, BL23, BLI2, BL43, CVI7, EX- } \\
\text { BI, ST36, LU7, LU5, ST40, SPI0 }\end{array}$ & $\begin{array}{c}\text { Warming } \\
\text { acupuncture }\end{array}$ & 3-4 Zhuang & 5 times a week & I \\
\hline $\begin{array}{l}\text { Suzuki } \\
M(20 I 2)^{23}\end{array}$ & $\begin{array}{c}\text { LUI, LU9, ST32, CV4, CVI2, ST36, } \\
\text { KI3, SI4, BLI3, BL20, BL23 }\end{array}$ & $\begin{array}{l}\text { Filiform needle } \\
\text { acupuncture }\end{array}$ & $50 \mathrm{~min}$ & Once a week & 12 weeks \\
\hline \multirow[t]{2}{*}{$\begin{array}{l}X u \text { YG } \\
(2008)^{24}\end{array}$} & \multirow[t]{2}{*}{ CVI7 } & $\begin{array}{l}\text { Big-needle } \\
\text { acupuncture }\end{array}$ & $4 \mathrm{~h}$ & \multirow[t]{2}{*}{5 times a week } & \multirow[t]{2}{*}{4 weeks } \\
\hline & & $\begin{array}{l}\text { Filiform needle } \\
\text { acupuncture }\end{array}$ & $30 \mathrm{~min}$ & & \\
\hline Lin LJ $(2015)^{25}$ & $\begin{array}{c}\mathrm{ST} 36, \mathrm{CV} 6, \mathrm{BLI} 3, \mathrm{BL} 20, \mathrm{BL} 23, \mathrm{EX}- \\
\mathrm{BI}\end{array}$ & $\begin{array}{l}\text { Warming } \\
\text { acupuncture }\end{array}$ & 5 Zhuang & Once a day & 8 weeks \\
\hline $\begin{array}{l}\text { Wu LL } \\
(2019)^{26}\end{array}$ & $\begin{array}{c}\text { BL2I, BL20, BL23, BLI3, LU9, KI3, } \\
\text { ST36 }\end{array}$ & $\begin{array}{l}\text { Filiform needle } \\
\text { acupuncture }\end{array}$ & $30 \mathrm{~min}$ & Once pre $12 \mathrm{~h}$ & l \\
\hline $\begin{array}{l}\text { Guan } \\
W(2016)^{16}\end{array}$ & $\begin{array}{c}\text { CVI2, CVI0, CV6, CV4, ST24, } \\
\text { ST25, SPI5, GB26 }\end{array}$ & $\begin{array}{l}\text { Abdominal } \\
\text { acupuncture }\end{array}$ & $30 \mathrm{~min}$ & $\begin{array}{l}\text { Once a day for the first } 3 \text { days; once } \\
\text { every other day for the next I I days }\end{array}$ & 14 days \\
\hline $\begin{array}{l}\text { Wang } \\
\text { Y }(2020)^{27}\end{array}$ & $\begin{array}{c}\text { CVI2, CVI0, CV4, ST25, GB26, } \\
\text { SPI5 }\end{array}$ & $\begin{array}{l}\text { Abdominal } \\
\text { acupuncture }\end{array}$ & $18 \mathrm{~min}$ & l & 2 weeks \\
\hline $\begin{array}{l}\text { Wang JY } \\
(2015)^{17}\end{array}$ & $\begin{array}{c}\text { ST36, ST40, SP6, SPI5, CVI2, } \\
\text { CVI3, CV6, CV4, LU9, LU5, LU6, } \\
\text { EX-BI }\end{array}$ & $\begin{array}{l}\text { Filiform needle } \\
\text { acupuncture }\end{array}$ & $30 \mathrm{~min}$ & Once a day & 40 days \\
\hline $\begin{array}{l}\text { Cheng YY } \\
(2017)^{28}\end{array}$ & $\begin{array}{c}\text { CVI2, CVI0, CV6, CV4, ST24, } \\
\text { ST25, SPI5, GB26 }\end{array}$ & $\begin{array}{l}\text { Abdominal } \\
\text { acupuncture }\end{array}$ & $30 \mathrm{~min}$ & $\begin{array}{l}\text { Once a day for the first } 3 \text { days; once } \\
\text { every other day for the next I I days }\end{array}$ & 7days \\
\hline
\end{tabular}

Note: /, not reported.

acupuncture to intervene patients with COPD. The improvement of DE, DTF, DE/TPIA dia, D-RSBI in the combined intervention group was significantly greater than that before the treatment and in the control group $(P$ value $<0.05)$.

\section{Pulmonary Function}

7 studies reported indicators of pulmonary ventilation function, including FVC, FEV1, FEV1/FVC, FEV1\% pred and MVV\%. ${ }^{16,17,22,23,25,27,28}$ One study reported vital capacity (VC). ${ }^{28}$

Relevant articles have confirmed that acupuncture has a positive effect on lung function while improving diaphragm function in COPD. In terms of improving pulmonary ventilation, 7 studies with different acupuncture schemes have observed significant improvements in ventilation function indicators such as FVC, FEV1\%pred, FEV1/FVC or MVV after intervention. ${ }^{16,17,22,23,25-28}$ Cheng et $\mathrm{al}^{28}$ also found that VC of patients with COPD increased significantly after five times of abdominal acupuncture combined with standard therapy; the improvement was more obvious than that of the control group, which only received standard therapy, indicating that acupuncture can also improve the lung volume of patients with COPD to a certain extent (see Table 2 for details).

\section{Hypoxia and Carbon Dioxide Retention}

In terms of arterial blood gas, seven studies reported $\mathrm{PaO}_{2}$ and $\mathrm{PaCO}_{2}$ in subjects before and after intervention. Five studies showed that both $\mathrm{PaO}_{2}$ and $\mathrm{PaCO}_{2}$ in the observation group were improved after intervention compared with baseline. $^{16,17,26-28}$ In inter-group comparison, Deng et $\mathrm{al}^{22}$ and $\mathrm{Wu}$ et $\mathrm{al}^{26}$ reported that the $\mathrm{PaO}_{2}$ and $\mathrm{PaCO}_{2}$ in the observation group were significantly better than those in the control group. Three studies only showed the advantage of the observation group in improving $\mathrm{PaO}_{2} \cdot{ }^{16,17,27}$ Suzuki et $\mathrm{al}^{23}$ only found that the change of $\mathrm{PaO}_{2}$ in the acupuncture group from baseline was statistically significant compared with that in the sham acupuncture group $(\mathrm{MD}=11.18$; $\mathrm{CI}$ : 4.70, 17.66; $P$ value $<0.001$ ) (see Table 2 for details). 


\section{Discussion}

\section{Rules of Acupoint Selection for} Acupuncture on Diaphragm Dysfunction in COPD

The rehabilitation effect of acupuncture on diseases is closely associated with acupuncture schemes. The final outcomes are affected by different inscapes of acupuncture. ${ }^{29}$ In this study, we hope to further discuss the rules of acupoint selection for acupuncture on diaphragm dysfunction in COPD by spotting the association between the analysis results of acupoint selection in above and the relevant theory of Traditional Chinese Medicine.

According to the theory of Traditional Chinese Medicine, the fundamental etiology of diaphragm dysfunction in COPD is the weakness of lung, spleen, and kidney. The specific pathogenesis is as follows: the lung is easily invaded by external pathogens due to the deficiency of lung qi, which induces COPD; the disease further leads to disorder of spleen and stomach, affects nutrient intake and absorption, and thus causes respiratory muscle fatigue. Therefore, the treatment for diaphragm dysfunction in COPD should obey the therapeutical principle that treat the manifestation and root cause of the disease. It means that in addition to improving diaphragm function specifically, invigorating spleen and benefiting lung should also be considered. ${ }^{30-33}$

We found that most of the studies followed the above treatment ideas after carrying out the association analysis on the seven high-frequency selected acupoints: 1) The running course of the meridians where the seven acupoints are located are related to lung, kidney, spleen, and stomach at different angles, acupuncture on them can strengthen the related viscera. ${ }^{34}$ 2) Based on the selection of acupuncture type (abdominal acupuncture was used in three studies) and the result of acupoint-site association analysis, we found that acupoints on the abdomen and back are selected more frequently, which is in line with the principle of acupuncture for viscera disorders: pay attention to local point selection. According to the theory of Traditional Chinese Medicine, the viscera in human body are connected with the back and the abdomen through meridians, the acupoints on the back or abdomen can reflect the state of the viscera and be used to regulate the viscera. ${ }^{35} 3$ ) During the acupoint-special acupoint association analysis, it is found that all seven highfrequency selected acupoints are special acupoints. Special acupoints refer to acupoints with special therapeutic effects: lower-he-sea point, yuan-primary point, and five-shu point have the effect of regulating viscera and connecting vascular-qi; back-shu point can not only treat corresponding visceral diseases but also treat musculoskeletal diseases related to viscera; crossing point is the acupoint at which two or several meridians intersect, acupuncture on it can stimulate all the meridians through it, which has the characteristic that one point can treat multi disease. ${ }^{36}$

In conclusion, we summarized the rules of acupoint selection for acupuncture on diaphragm dysfunction in COPD: (1) following the treatment idea of Traditional Chinese Medicine that invigorating spleen and benefiting lung, treating the manifestation and root cause of disease; (2) the main acupuncture sites are abdomen and back; (3) mostly choosing acupoints on the meridians related to lung, kidney, spleen, and stomach; (4) having the characteristics of combining local point selection with specific point selection (Figure 2).

\section{Rehabilitation Effect of Acupuncture on Diaphragm Dysfunction in COPD}

COPD can cause diaphragm fiber transform from fasttwitch fiber with strong explosive force and poor endurance to slow-twitch fiber with strong anti-fatigue ability and low contractility, accompanied with the imbalance between anabolism and catabolism of diaphragm myofibers. This kind of fiber remodeling and atrophy will inevitably lead to the decrease in diaphragm muscle strength. $^{37,38}$ Among the included studies, MIP and ARMM were selected to assess diaphragm function. MIP is often used to evaluate the diaphragm strength in clinic, and it is considered to be a great indicator to indicate the contractility of diaphragm; ${ }^{39}$ AMRR was first proposed by Ward Patrick. ${ }^{40}$ Since the contractile intensity of the auxiliary respiratory muscle is negatively correlated with the functional activity of the main respiratory muscle, it can be used to measure the diaphragm strength and reflect the fatigue degree of the respiratory muscle by evaluating the contractile activity of the auxiliary respiratory muscle located in the neck, shoulder, back. Significant differences between groups were observed in the MIP or ARMM reported in all nine studies, regardless of whether the participants with stable COPD or AECOPD. It is corroborated that, in the same intervention period, adding acupuncture to the standard therapy plan can ameliorate the decrease in diaphragm muscle strength and respiratory muscle fatigue of patients with COPD and improve the rehabilitation efficiency. One study offered that the effective stimulating amount of acupuncture determined by 


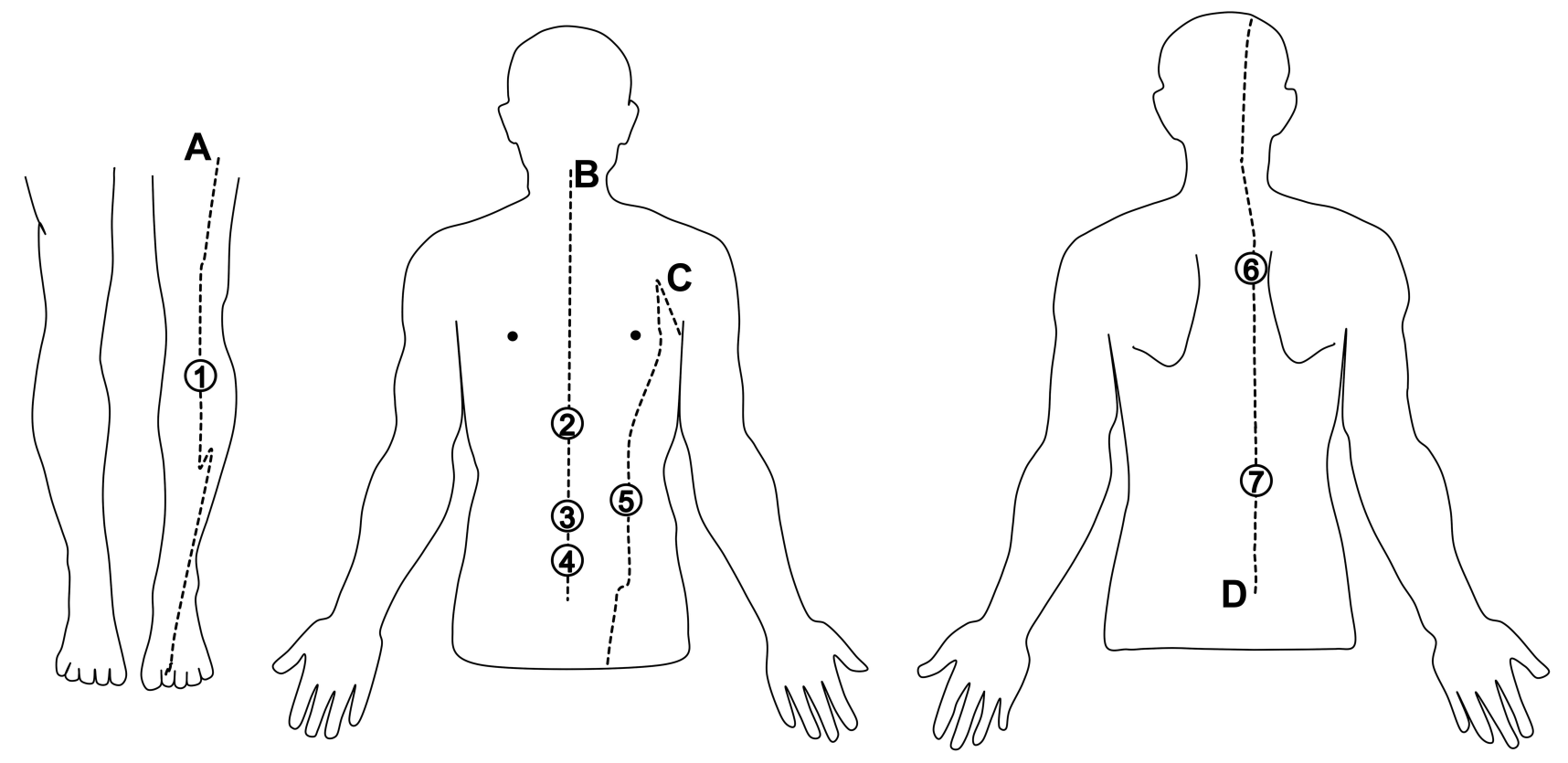

Figure 2 High-frequency selected acupoints.

Notes: a, Yangming Stomach Meridian of Foot; (1), ST36; b, Ren Meridian; (2), CV2; (3), CV6; (4), CV4; c, Taiyin Spleen Meridian of Foot; (5), SPI5; d, Taiyang Bladder Meridian of Foot; (6), BLI3; (7), BL23.

acupuncture time and acupuncture intensity would affect the acupuncture efficiency. ${ }^{24}$ The researchers thought that long-term and high-intensity acupuncture could improve the diaphragm muscle strength of patients with COPD more obviously than conventional acupuncture, but the evidence supporting this view is limited and needs to be explored further.

Patients in the COPD with diaphragm dysfunction generally perform weakened diaphragm contraction ability and decreased diaphragm movement due to diaphragm atrophy, increased airway resistance, and limited gas exchange. Although $\mathrm{Wu}$ et $\mathrm{al}^{26}$ used a combined intervention of acupuncture and Shenmai injection, but the significant changes of DE, DE/TPIA $A_{\text {dia }}$ and D-RSBI observed after the intervention, still illustrated that acupuncture may have a positive effect on diaphragmatic motor performance in COPD.

Apart from the abnormal variations in the diaphragm structure, changes in the external environment around the diaphragm brought about by COPD limit the functional performance of the diaphragm. Airway wall structural remodeling due to repeated inflammation can lead to airway obstruction, which in turn causes lung overinflation. Lung overinflation, on the one hand, will shorten the initial length of the diaphragm sarcomere and change the diaphragmatic strength; on the other hand, it can cause changes in lung volume and compliance, resulting in increased diaphragmatic load and restricting diaphragm movement in space. ${ }^{41,42}$ The outcomes of a clinical trial showed that forced expiratory volume in FEV1\%pred, FEV1/FVC and other pulmonary function indicators of patients with COPD were significantly correlated with transdiaphragmatic pressure, diaphragmatic electromyogram signal, and other indices reflecting diaphragm work or diaphragm electromyographic activity, which further showed the close relationship between COPD pulmonary function and diaphragm function. ${ }^{43}$ Results of 7 studies that reported lung function indicators showed that acupuncture improved lung function to varying degrees in patients in the COPD with diaphragm dysfunction, it is not only demonstrates that the airflow limitation of COPD is not completely irreversible but also suggests that affecting the environment suffering diaphragm, such as pulmonary ventilation capacity and lung volume, may be an indirect way for acupuncture to improve the diaphragm function of patients with COPD.

Owing to ventilation dysfunction and gas exchange dysfunction, patients with COPD may experience different severity of hypoxia and carbon dioxide retention, then exhibit hypoxemia and hypercapnia. ${ }^{44}$ This condition can cause the changes in histological morphology and movement of diaphragm, resulting in diaphragm fatigue. ${ }^{45}$ 
Diaphragm fatigue can lead to insufficient ventilation drive and aggravate the limitation of gas exchange, forming a vicious circle and causing respiratory failure. ${ }^{9,46,47}$ Seven of the nine included studies reported $\mathrm{PaO}_{2}$ and $\mathrm{PaCO}_{2}$, and significant differences of the two indicators were observed within or between groups. $\mathrm{PaO}_{2}$ and $\mathrm{PaCO}_{2}$ are the two main indices of arterial blood gases, which reflect the condition of hypoxia and carbon dioxide retention. They also be used as clinical diagnostic criteria for respiratory failure. When $\mathrm{PaO}_{2}<60 \mathrm{mmHg}$ or $\mathrm{PaCO}_{2}$ $>45 \mathrm{mmHg}$, the patients will be diagnosed with respiratory failure. ${ }^{46}$ By combining changes in parameters of diaphragm function and arterial blood gases in existing literature, we speculate that acupuncture can relieve diaphragm fatigue through improving the hypoxia state and pulmonary ventilation ability of patients with COPD; acupuncture may also play a preventive and alleviating role in respiratory failure caused by diaphragm dysfunction.

\section{Possible Mechanism of Acupuncture on Diaphragm Dysfunction in COPD Inflammatory Reaction}

The GOLD still emphasized in the 2020 report on the Global Strategy for COPD diagnosis, treatment and prevention that inflammatory response caused by chronic irritants may be closely related to some complications of COPD. ${ }^{1}$ Evidence shows that the inflammatory reaction in COPD will directly or indirectly affect the respiratory muscle function of patients: chronic irritants can activate and increase the levels of proinflammatory cytokines, such as tumor necrosis factor $\alpha(\mathrm{TNF}-\alpha)$. These inflammatory factors regulate the activity level of ubiquitin-proteasome system (UPS) by mediating the expression of NF- $\kappa B$, MAPK, and other pathways, thereby promoting the diaphragm to proteolysis and shift from metabolic balance to catabolism. ${ }^{48-50}$ TNF- $\alpha$ can also induce diaphragm cell apoptosis by activating the caspase- 3 protein by binding to the receptor and eventually cause diaphragm atrophy. ${ }^{51}$

Some studies have demonstrated that acupuncture can effectively reduce the content of TNF- $\alpha$ in diaphragm tissue of rats with respiratory muscle fatigue in COPD. ${ }^{52}$ Chen et $\mathrm{al}^{15}$ also found that electroacupuncture can significantly reduce the expression of ubiquitin protein ligase atrogin-1, MuRF-1, and striated muscle differentiation protein MyoD in the diaphragm tissue of COPD model rats. Based on the above research results, acupuncture may down-regulate atrogin-1 and MuRF-1 of UPS by reducing proinflammatory cytokines in diaphragm tissue to inhibit the diaphragm protein degraded by UPS and alleviate dysfunction caused by diaphragm atrophy.

\section{Oxidative Stress}

Oxidative stress is common in COPD and considered an important amplifying mechanism in COPD. ${ }^{1}$ The oxide/antioxidant metabolism imbalance can damage to diaphragm tissue. ${ }^{53}$ Increase in the level of reactive oxygen species (ROS) in diaphragm tissue of rats exposed to smoke for a long time leads to oxide metabolism imbalance. Excess ROS may regulate protein degradation by activating various intracellular signaling pathways. The phenomenon can also directly alter diaphragm protein structure through carbonylation modification of amino acid residues, ultimately causing oxidative damage to the diaphragm. ${ }^{54-56}$ Acupuncture can effectively alleviate oxidative stress in COPD. The possible path of action is to promote the dynamic balance of antioxidant enzyme systems, such as SOD/LPO, NOS/NO, and $\mathrm{GSH} / \mathrm{GSSG}$, or regulate nicotinamide adenine dinucleotide phosphate (NADPH) oxidase and the respiratory chain complexes in mitochondrial, which are related to ROS production and elimination. ${ }^{57,58}$

Through an experimental research, ${ }^{52}$ Chinese investigators found that the activity of cytochrome oxidase, NADPH oxidase, and succinate dehydrogenase in the mitochondrial suspension of diaphragm tissue from COPD rats in the abdominal acupuncture group that received acupuncture was higher than that in the model group, and the difference between the two groups was statistically significant. Hence, acupuncture may improve diaphragm function by increasing the activities of NADPH oxidase and respiratory chain complexes in mitochondrial to down-regulating diaphragm protein damage caused by ROS overexpression.

\section{Neural Respiratory Drive}

The diaphragm is regulated by the central nervous system. In a certain range, higher level of neural respiratory drive (NRD) leads to higher contraction intensity of the diaphragm. The researchers believe that this mechanism is used to compensate for the diaphragm dysfunction in COPD, in which increasing respiratory drive to meet ventilation needs. ${ }^{59}$ However, long-term over drive may reversely aggravate diaphragm fatigue and further affect the respiratory function in patients with COPD. ${ }^{60}$

Some studies have explored the neural molecular mechanism of the NRD changes in COPD and found that 
orexin (OX) plays an important role. OX is a kind of neuropeptide. When OX binds to its receptors in the Bötzinger complex of medulla oblongata, it can increase the level of NRD and the electromyographic activity of the diaphragm. ${ }^{61-63}$ Liu $\mathrm{ZB}^{64}$ found that the excitation effect on phrenic nerve induced by $\mathrm{OX}$ and the expression of orexin and orexin receptor protein in rats with COPD were significantly increased due to COPD. He thought that $\mathrm{OX}$ may be involved in the pathophysiology of COPD and regulate the NRD to diaphragm. Zhang et $\mathrm{al}^{65}$ performed electroacupuncture on BL13 and ST36 of COPD rats for 2 weeks and found that the expression of orexin and its receptors in the hypothalamus and the medulla were decreased in response to intervention, along with the improvement of respiratory frequency and lung ventilatory capacity. Taking the above evidence together, we speculate that acupuncture may participate in the central neural regulation of diaphragm activity in COPD by affecting the OX system. However, the specific mechanism still needs to be further explored.

In conclusion, we summarized some potential mechanisms of acupuncture on diaphragm dysfunction in COPD (Figure 3).

\section{Strengths and Limitations}

This study focused on the rehabilitation effect of acupuncture on diaphragm dysfunction, which is the main extrapulmonary effect of COPD, and excluding the heterogeneity caused by other non-invasive acupoint treatments (acupressure, moxibustion, acupoint application, etc.). Our results further clarified the impacts of acupuncture in COPD treatment. The summary of the acupuncture schemes could provide a reference for its application in improving the diaphragm function of COPD patients.

However, several limitations exist in this study: 1) the design of acupuncture schemes across included studies has obvious differences; 2) Indicators selection: MIP is widely used as an effectively indicator to reflect the alteration of diaphragm muscle strength in the evaluation of diaphragm function, the scale for accessory respiratory muscle mobilization has also been used in multiple studies in China to reflect the main respiratory muscle fatigue. However, only using the two indicators to reflect diaphragm functional state is one-sided, and they respectively suffer from limited objectivity and insufficient sensitivity; 3) Blinding: due to the characteristics of acupuncture operations, it is difficult to achieve blinding for subjects and assessors, which may introduce implementation bias.

\section{Conclusion}

In this review, we identified studies related to the effect of acupuncture on diaphragm dysfunction in COPD and then reorganized acupuncture schemes and rehabilitation effects. The acupuncture schemes for diaphragm dysfunction in COPD are not uniform and lacks authority and guidance. We conclude a possible acupoint selection idea

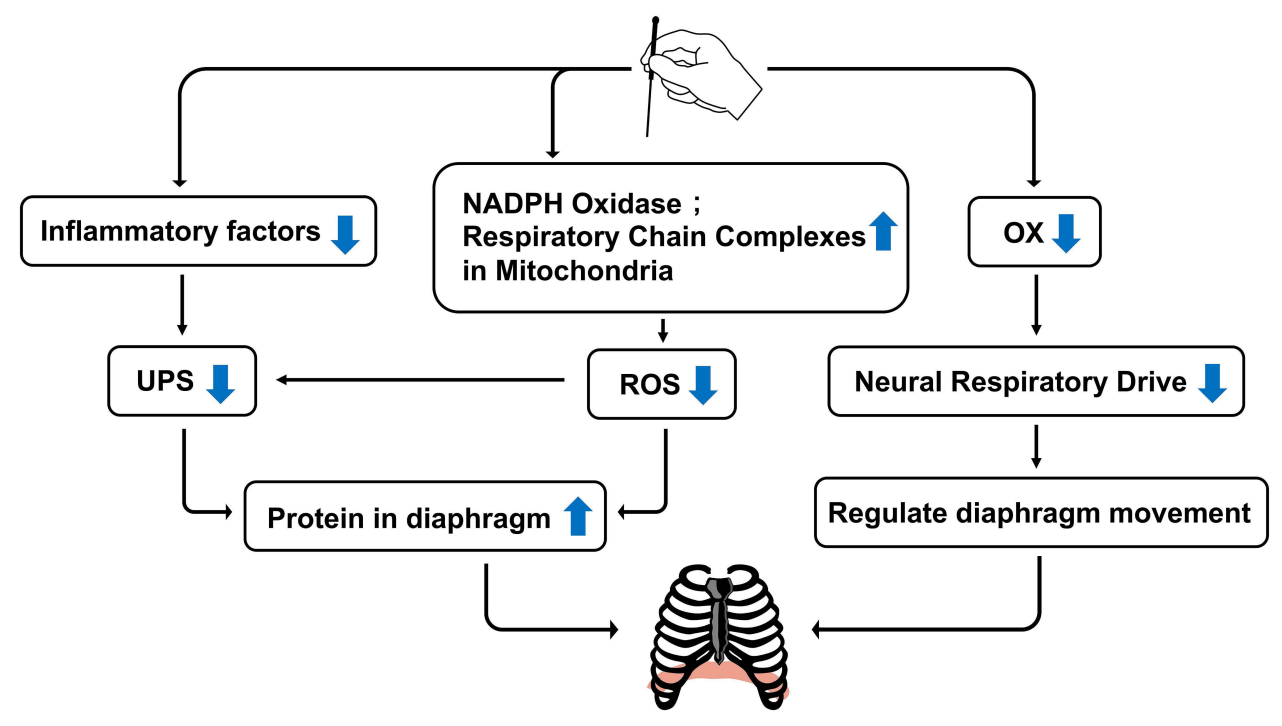

Figure 3 Mechanism of acupuncture on diaphragm dysfunction in COPD.

Notes: On the one hand, acupuncture inhibits UPS activity by downregulating proinflammatory factors or reduce ROS production by upregulating NADPH oxidase and respiratory chain complexes in mitochondrial to regulate the inflammatory response and oxidative stress on diaphragm protein degeneration and damage; on the other hand, acupuncture may reduce neural respiratory drive by regulating OX content to affect diaphragm activity. 
after analyzing the acupoints used in each study, that is, combining local point selection with picking specific points to regulate lung, spleen, kidney, and stomach while picking local points to stimulate diaphragm, so as to treating the manifestation and root cause of COPD. We hope that this work can provide reference for subsequent research and clinical application.

In terms of rehabilitation effects, acupuncture has positive effects on enhancing diaphragm muscle strength and increasing the work of respiratory muscle, whether patients with COPD are in stable or acute exacerbation stage. Acupuncture also could provide great boost to lung function, hypoxia, and carbon dioxide retention. We have found the possibility of using acupuncture to prevent and relieve respiratory failure, a complication of diaphragmatic dysfunction in COPD. The above findings are limited by the heterogeneity of the acupuncture scheme and the small number of included studies in the review, but these findings remain positive and worthy of further exploration. Moreover, we discussed the potential mechanism and found that acupuncture may participate in the rehabilitation of diaphragm dysfunction in COPD by regulating inflammatory response, oxidative stress, or NRD.

\section{Future Direction}

The symptoms in different stages of COPD are diverse, and individual differences in patients exist; the treatment principle is that Traditional Chinese Medicine stress on, such as "treatment based on syndrome differentiation" and 'treatment in accordance with three categories of etiologic factors'. Hence, a challenge needs to be solved when we apply acupuncture on diaphragm dysfunction in COPD. The acupuncture scheme lacks uniform standards and have poor clinical reproducibility. To cope with this, we provide a train of thought, which is whether we can divide subjects according to different performance characteristics of patients with COPD in the future research, on the basis of ensuring sufficient sample size, to explore the optimal acupuncture scheme for different performance characteristics of COPD.

In addition, to deal with the limitations of evaluation indicators selection in current relevant studies, we consider that multivariate and safe methods, such as ultrasound, in combination with indicators having stronger specificity and multi-angle such as diaphragm mobility, diaphragm thickness, should be chosen in future studies, to prove the effect of acupuncture on diaphragm function in COPD comprehensively.

\section{Acknowledgments}

The authors really appreciate the help of people from Shanghai University of Traditional Chinese Medicine.

\section{Funding}

This review was supported by the National Natural Science Foundation of China (Grant No 81902307, 82072551); Shanghai Health Commission accelerated the development of traditional Chinese medicine three-year action plan project [Grant No. ZY(2018-2020)-CCCX -2001-06/2004-05]; Shanghai Education Foundation Project "Effect of pulmonary-based Qigong rehabilitation protocol on pulmonary function and quality of life of discharged patients with COVID-19".

\section{Disclosure}

The authors report no conflicts of interest in this work.

\section{References}

1. Global initiative for chronic obstructive lung disease. Global strategy for the diagnosis, management, and prevention of chronic obstructive pulmonary disease; 2020. Available from: https://goldcopd.org. Accessed June 19, 2021.

2. Halpin Dmg, Celli BR, Criner GJ, et al. The GOLD Summit on chronic obstructive pulmonary disease in low- and middle-income countries. Int J Tuberc Lung Dis. 2019;23(11):1131-1141. doi:10. 5588/ijtld.19.0397

3. Wang C, Xu J, Yang L, et al. Prevalence and risk factors of chronic obstructive pulmonary disease in China (the China Pulmonary Health [CPH] study): a national cross-sectional study. Lancet. 2018;391 (10131):1706-1717. doi:10.1016/S0140-6736(18)30841-9

4. Polkey MI, Kyroussis D, Hamnegard CH, Mills GH, Green M, Moxham J. Diaphragm strength in chronic obstructive pulmonary disease. Am J Respir Crit Care Med. 1996;154(5):1310-1317. doi:10.1164/ajrccm.154.5.8912741

5. Ottenheijm CA, Heunks LM, Sieck GC, et al. Diaphragm dysfunction in chronic obstructive pulmonary disease. Am J Respir Crit Care Med. 2005;172(2):200-205. doi:10.1164/rccm.200502-262OC

6. Souza RMP, Cardim AB, Maia TO, Rocha LG, Bezerra SD, Marinho PÉM. Inspiratory muscle strength, diaphragmatic mobility, and body composition in chronic obstructive pulmonary disease. Physiother Res Int. 2019;24(2):e1766. doi:10.1002/pri.1766

7. Ottenheijm CA, Heunks LM, Dekhuijzen RP. Diaphragm adaptations in patients with COPD. Respir Res. 2008;9(1):12. doi:10.1186/14659921-9-12

8. Boon AJ, O'Gorman C. Ultrasound in the Assessment of Respiration. J Clin Neurophysiol. 2016;33(2):112-119. doi:10.1097/WNP.000000 0000000240

9. Zielinski J, MacNee W, Wedzicha J, et al. Causes of death in patients with COPD and chronic respiratory failure. Monaldi Arch Chest Dis. 1997;52(1):43-47.

10. Lötters F, van Tol B, Kwakkel G, Gosselink R. Effects of controlled inspiratory muscle training in patients with COPD: a meta-analysis. Eur Respir J. 2002;20(3):570-576. doi:10.1183/09031936.02.0023 7402

11. American Thoracic Society. Pulmonary rehabilitation-1999. Am J Respir Crit Care Med. 1999;159(5 Pt 1):1666-1682. doi:10.1164/ ajrccm.159.5.ats2-99. 
12. Du YH, Li J, Sun DW, et al. Study on modern disease menu of acupuncture and moxibustion therapy in China. Chin Acupuncture Moxibustion. 2007;27(5):373-378.

13. Ge Y, Yao H, Tong J, He Y, Li G, Kong X. Effects of acupuncture on peripheral skeletal muscle exercise ability in patients with chronic obstructive pulmonary disease at stable phase. Chin Acupuncture Moxibustion. 2017;37(4):366-371. doi:10.13703/j.0255-2930.2017.04.005.

14. Tong J, Li GY, He Y, et al. Effect of acupuncture on lung recovery in chronic obstructive pulmonary disease and its safety analysis. Shanghai J Acupuncture Moxibustion. 2017;36(08):923-928. doi:10. 13460/j.issn.1005-0957.2017.08.0923

15. Chen JX, Liu CS, He Y, et al. Regulatory mechanism of electroacupuncture therapy for diaphragm function of chronic obstructive pulmonary disease model rats with muscular dystrophy. $J$ Guangzhou Univ Trad Chin Med. 2018;35(2):265-271. doi:10.13359/j.cnki. gzxbtcm.2018.02.014

16. Guan W, Guo N, Shang F. Effect of abdominal acupuncture on the respiratory muscle fatigue model with chronic obstructive pulmonary disease. J Emerg Trad Chin Med. 2016;25(1):68-71.

17. Wang JY, Yu WJ. The effect of Shengjin acupuncture therapy on patients with acute exacerbation type of COPD. J Emerg Trad Chin Med. 2015;24(4):728-730.

18. Coyle ME, Shergis JL, Huang ET, et al. Acupuncture therapies for chronic obstructive pulmonary disease: a systematic review of randomized, controlled trials. Altern Ther Health Med. 2014;20 (6): $10-23$.

19. Fernández-Jané C, Vilaró J, Fei Y, et al. Filiform needle acupuncture for COPD: a systematic review and meta-analysis. Complement Ther Med. 2019;47:102182. doi:10.1016/j.ctim.2019.08.016

20. Zhang LX, Tian YG, Ma JD, et al. Progress of acupuncture treatment of chronic obstructive pulmonary disease. China J Trad Chin Med Pharm. 2019;34(2):705-707.

21. Maher CG, Sherrington C, Herbert RD, Moseley AM, Elkins M. Reliability of the PEDro scale for rating quality of randomized controlled trials. Phys Ther. 2003;83(8):713-721. doi:10.1093/ptj/ 83.8.713

22. Deng YQ, Zou HY, Chen Y. The effect of warm acupuncture moxibustion on respiratory muscle fatigue in patients with chronic obstructive pulmonary disease. Inner Mongolia J Trad Chin Med. 2019;38(3):64-65. doi:10.16040/j.cnki.cn15-1101.2019.03.043.

23. Suzuki M, Muro S, Ando Y, et al. A randomized, placebo-controlled trial of acupuncture in patients with chronic obstructive pulmonary disease (COPD): the COPD-acupuncture trial (CAT). Arch Intern Med. 2012;172(11):878-886. doi:10.1001/archinternmed.2012.1233

24. Xu YG, Lei S, Xuan LH, et al. Effect of big needle acupuncture at Tanzhong on respiratory muscle fatigue in patients with chronic obstructive pulmonary disease. Chin J Trad Med Sci Technol. 2008;15(1):66-67.

25. Lin LJ. Observation on effect of acupuncture and medicine combined therapy on respiratory muscle fatigue in stable COPD. Modern Diagn Treatment. 2015;26(06):1244-1245.

26. Wu LL, Guo HY. Effect of Shenmai injection combined with acupuncture on the difficulty of mechanical ventilation weaning in COPD with respiratory failure and its effects on diaphragmatic function, NT-proBNP and ha-CRP. Modern J Integrated Trad Chin Western Med. 2019;28(29):3233-3238.

27. Wang Y, Li CS. Clinical efficacy of abdominal acupuncture for respiratory muscle fatigue in acute exacerbation of chronic obstructive pulmonary disease. PSY. 2020;15(11):218. doi:10.19738/j.cnki. psy.2020.11.193

28. Cheng YY. Study on clinical curative effect of abdominal needle on treatment to COPD exacerbations period [dissertation]. Taiyuan: Shanxi University of Chinese Medicine; 2017. (Chinese).

29. Wu HJ. Acupoint and therapy efficacy of acupuncture-moxibustion [J]. Chin J Integr Trad Western Med. 2012;32(11):1452-1457.
30. Zhu HZ, Han MX. Pathogenesis of viscera in chronic obstructive pulmonary disease. Chin Arch Trad Chin Med. 2005;20 (6):1042-1043. doi:10.13193/j.archtcm.2005.06.84.zhuhzh.033.

31. Sun P, Ding YP. Risk factors and pathogenesis of COPD: a review. Hainan Med J. 2015;25(9):9.

32. Ye ZY. Contribution of Lingshu Jingmai article to acupuncture theory. J Clin Acupuncture Moxibustion. 2002;18(5):2-3.

33. Yan XG, Wu GF, Huang F, et al. Progress of TCM treatment of chronic obstructive pulmonary disease in stable phase. Acta Chin Med. 2016;31 (9):1284-1288. doi:10.16368/j.issn.1674-8999.2016.09.361

34. Hebei Medical University. Interpretation of Miraculous Pivot (2nd edition). People's Medical Publishing House; 2011. (Chinese.)

35. Hua S, Zhou FX, Li YH. Annotation for Gist of the Classic of Questioning. Henan Science and Technology Press; 2015. (Chinese).

36. Zhao JP, Wang YP. Acupuncture on special points: theory and clinic. Scientific and Technical Documentation Press; 2005. (Chinese).

37. Testelmans D, Crul T, Maes K, et al. Atrophy and hypertrophy signalling in the diaphragm of patients with COPD. Eur Respir J. 2010;35(3):549-556. doi:10.1183/09031936.00091108

38. Levine S, Bashir MH, Clanton TL, Powers SK, Singhal S. COPD elicits remodeling of the diaphragm and vastus lateralis muscles in humans. J Appl Physiol (1985). 2013;114(9):1235-1245. doi:10. 1152/japplphysiol.01121.2012

39. Zhou LN, Huang QY, Huang SG. Research progress of comprehensive assessment methods for diaphragmatic dysfunction. Chin J Tuberc Respir Dis. 2019;37(02):115-118. doi:10.3760/cma.j. issn.1001-0939.2014.02.011.

40. Patrick W, Webster K, Ludwig L, Roberts D, Wiebe P, Younes M. Noninvasive positive-pressure ventilation in acute respiratory distress without prior chronic respiratory failure. Am J Respir Crit Care Med. 1996;153(3):1005-1011. doi:10.1164/ajrccm.153.3.8630538

41. Orozco-Levi M, Gea J, Lloreta JL, et al. Subcellular adaptation of the human diaphragm in chronic obstructive pulmonary disease. Eur Respir J. 1999;13(2):371-378. doi:10.1183/09031936.99.13237199

42. Similowski T, Yan S, Gauthier AP, Macklem PT, Bellemare F, Contractile properties of the human diaphragm during chronic hyperinflation. $N$ Engl J Med. 1991;325(13):917-923. doi:10.1056/ NEJM199109263251304

43. Qin YY, Liu YQ, Zhang DH, et al. Correlation between decline of pulmonary function and changes of diaphragmatic function in patients with chronic obstructive pulmonary disease. Chin J Biomed Eng. 2017;2017(05):369-373. doi:10.3760/cma.j.issn.16741927.2017.05.003

44. Li Y, Tian YG, Li SY. Diaphragmatic fatigue in COPD: a review. Chin J Gerontol. 2014;34(01):263-265.

45. Shiota S, Okada T, Naitoh H, Ochi R, Fukuchi Y. Hypoxia and hypercapnia affect contractile and histological properties of rat diaphragm and hind limb muscles. Pathophysiology. 2004;11(1):23-30. doi:10.1016/j.pathophys.2003.09.003

46. Roussos C, Koutsoukou A. Respiratory failure. Eur Respir J Suppl. 2003;47:3s-14s. doi:10.1183/09031936.03.00038503

47. Wang TJ, Xu WG, Luo Y. Study on relationship between respiratory muscle strength and arterial blood gas analysis in patient with COPD accompanied respiratory failure. Modern Rehabil. 2001;5 (8):53-57.

48. Jackman RW, Cornwell EW, Wu CL, Kandarian SC. Nuclear factor-kB signalling and transcriptional regulation in skeletal muscle atrophy. Exp Physiol. 2013;98(1):19-24. doi:10.1113/expphysiol.2011.063321

49. Haegens A, Schols AM, Gorissen SH, et al. NF-kB activation and polyubiquitin conjugation are required for pulmonary inflammationinduced diaphragm atrophy. Am J Physiol Lung Cell Mol Physiol. 2012;302(1):L103-L110. doi:10.1152/ajplung.00084.2011

50. Koistinen HA, Chibalin AV, Zierath JR. Aberrant p38 mitogen-activated protein kinase signalling in skeletal muscle from Type 2 diabetic patients. Diabetologia. 2003;46(10):1324-1328. doi:10.1007/s00125-003-1196-3 
51. He X, Wu YJ, Yu GG, et al. Apoptosis of diaphragmatic muscle cell in mice with chronic obstructive pulmonary disease. J Clin Exp Med. 2018;17(22):2356-2360.

52. Guan W, Guo N, Shang F. The effect of abdominal acupuncture on respiratory muscle fatigue in acute exacerbation of chronic obstructive pulmonary disease. J Emerg Trad Chin Med. 2016;25(1):68-71.

53. Fischer BM, Voynow JA, Ghio AJ. COPD: balancing oxidants and antioxidants. Int J Chron Obstruct Pulmon Dis. 2015;10:261-276. doi:10.2147/COPD.S42414

54. Pomiès P, Blaquière $\mathrm{M}$, Maury J, Mercier J, Gouzi F, Hayot M. Involvement of the FoxO1/MuRF1/Atrogin-1 signaling pathway in the oxidative stress-induced atrophy of cultured chronic obstructive pulmonary disease myotubes. PLoS One. 2016;11(8):e0160092. doi:10.1371/journal.pone.0160092

55. Ma YC, Xu SS, Zhu R, et al. Effect of AMPK expression of ubiquitin-protein ligase mRNA mediated by Akt/FoxO phosphorylation in rat's skeletal muscle. J Beijing Sport Univ. 2016;39(6):57-62. doi:10.19582/j.cnki.11-3785/g8.2016.06.009

56. Barreiro E, de la Puente B, Minguella J, et al. Oxidative stress and respiratory muscle dysfunction in severe chronic obstructive pulmonary disease. Am J Respir Crit Care Med. 2005;171(10):1116-1124. doi:10.1164/rccm.200407-8870C

57. McDonald JL, Cripps AW, Smith PK, Smith CA, Xue CC, Golianu B. The anti-inflammatory effects of acupuncture and their relevance to allergic rhinitis: a narrative review and proposed model. Evid Based Complement Alternat Med. 2013;2013:591796. doi:10.1155/2013/591796

58. Yao QP, Dong KZ. Effect of combination of acupuncture and medicine on serum oxidation indexes and pulmonary function during remission stage of chronic obstructive pulmonary disease of lung-kidney deficiency type. Shanxi J Trad Chin Med. 2017;33(1):29-31.
59. Jolley CJ, Luo YM, Steier J, et al. Neural respiratory drive in healthy subjects and in COPD. Eur Respir J. 2009;33(2):289-297. doi:10.1183/09031936.00093408

60. Li Y, Li YH, Luo YW, et al. Effects of inhaled short-acting bronchodilators on diaphragm function and neural respiratory drive during maximal isocapnic ventilation in patients with chronic obstructive pulmonary disease. J Southern Med Univ. 2016;36(2):232-237. doi:10.1016/j.chest.2016.02.404

61. Young JK, Wu M, Manaye KF, et al. Orexin stimulates breathing via medullary and spinal pathways. J Appl Physiol (1985). 2005;98 (4):1387-1395. doi:10.1152/japplphysiol.00914.2004

62. Shahid IZ, Rahman AA, Pilowsky PM. Intrathecal orexin A increases sympathetic outflow and respiratory drive, enhances baroreflex sensitivity and blocks the somato-sympathetic reflex. $\mathrm{Br} J$ Pharmacol. 2011;162(4):961-973. doi:10.1111/j.1476-5381.2010.01102.x

63. Nakamura A, Zhang W, Yanagisawa M, Fukuda Y, Kuwaki T. Vigilance state-dependent attenuation of hypercapnic chemoreflex and exaggerated sleep apnea in orexin knockout mice. J Appl Physiol (1985). 2007;102 (1):241-248. doi:10.1152/japplphysiol.00679.2006

64. Liu ZB. The study of orexin on central respiratory regulation in chronic obstructive pulmonary disease rat and acupuncture therapy [dissertation]. Shanghai: Fudan University; 2009. (Chinese).

65. Zhang XF, Qin Q, Geng WY, et al. Electroacupuncture reduces hypothalamic and medullary expression of orexins and their receptors in a rat model of chronic obstructive pulmonary disease. Acupunct Med. 2018;36(5):312-318. doi:10.1136/acupmed-2017-011391

\section{Publish your work in this journal}

The International Journal of COPD is an international, peer-reviewed journal of therapeutics and pharmacology focusing on concise rapid reporting of clinical studies and reviews in COPD. Special focus is given to the pathophysiological processes underlying the disease, intervention programs, patient focused education, and self management protocols. This journal is indexed on PubMed Central, MedLine and CAS. The manuscript management system is completely online and includes a very quick and fair peer-review system, which is all easy to use. Visit http://www.dovepress.com/testimonials.php to read real quotes from published authors. 